Ending the School-to-Prison Pipeline: Perception and Experience with Zero-Tolerance Policies and Interventions to Address Racial Inequality

Kade-Ann K. Henry ${ }^{1}$, Robyn M. Catagnus ${ }^{1}$, Annette K. Griffith ${ }^{1}$, Yors A. Garcia ${ }^{1}$

${ }^{1}$ The Chicago School of Professional Psychology

\begin{abstract}
Author Notes
Kade-Ann K. Henry (ib https://orcid.org/0000-0002-9122-9868

Conflict of Interest: On behalf of all authors, the corresponding author states that there is no conflict of interest. Correspondence concerning this article should be addressed to Dr. Robyn Catagnus, Applied Behavior Analysis Department, 325 N Wells St, Chicago, IL 60654. Email: rcatagnus@thechicagoschool.edu
\end{abstract}




\begin{abstract}
This study expands the current research on anti-Black racism and student discipline in schools. It examines perception, experiences, and alternatives of zero-tolerance policies in education, in relation to the call for action by Black Lives Matter at Schools. Black, Indigenous, and People of Color (BIPOC) students are impacted at a disproportionate rate when it comes to school discipline, leading to high, inequitable incarceration rates. However, behavior analysis already has powerful tools and interventions that can stop this 'school-to-prison pipeline' effect. A survey of school professionals investigated awareness of adverse outcomes from zero-tolerance policies and the use of effective, behavioral alternatives to exclusionary disciplinary practices. Results confirmed zero-tolerance policies still exist in North American schools, but that school professionals, including behavior analysts, support Black Lives Matter at School's call to end such practices. Importantly, participants report already having the necessary skills to combat zero-tolerance; however, many still feel uncomfortable or ill-prepared to implement interventions specifically to decrease anti-Black racism in schools.
\end{abstract}

Keywords: accompliceship, anti-Black racism, applied behavior analysis, education, systemic racism, zerotolerance 
This manuscript is being published on an expedited basis, as part of a series of emergency publications designed to help practitioners of applied behavior analysis take immediate action to address police brutality and systemic racism.

The journal would like to especially thank Alison Szarko for their insightful and expeditious reviews of this manuscript. The views and strategies suggested by the articles in this series do not represent the positions of the Association for Behavior Analysis, International or Springer Nature.

Guest Editor, Denisha Gingles 


\section{Ending the School-to-Prison Pipeline: Perception and Experience with Zero-Tolerance Policies and Interventions to Address Racial Inequality}

The most recent deaths of unarmed Black men and women at the hands of the police have underscored an ongoing systemic problem within our society and intensified awareness and outrage of racism and racial inequality. Such events draw attention to the barriers and disparate treatment that Black, Indigenous, and People of Color (BIPOC) individuals face across various life domains. Inequity and racism are not new; civil rights advocates have made calls for attention and intervention for hundreds of years. Yet, the sequence of current events, including a world-wide pandemic, has disproportionately affected BIPOC both physically and economically. The events stimulated a renewed sense of duty among behavior analytic professionals to advocate and act for change. The field of behavior analysis must be more involved in understanding racism and racist behavior at the individual and societal levels, and work as members of multidisciplinary teams to create change (e.g., Matsuda et al., 2020; Mattaini \& Rehfeldt, 2020). While professionals need to act across a variety of areas, reducing systemic racism in the educational system is particularly critical. Black students receive exclusionary discipline at an inequitable rate compared to white students. Their behaviors are often punished more severely with consequences that often lead to the criminal justice system (National Association of Education, 2020). With the inequity that exists with disciplinary actions in education, it is important to come together and build accompliceship, a critical component in the efforts to dismantle systemic racism and promote equal rights. Accompliceship is established through continued supportive efforts, involving being "explicit", "accountable," and "responsible" in taking direct actions of togetherness right beside individuals facing cultural injustices (Indigenous Action, 2014, in Acts of Resignation).

\section{Inequities in Discipline for BIPOC Students}

In the 2013-2014 academic year, researchers estimated 2.6 million public school students received one or more out-of-school suspensions (U.S. Department of Education, 2019). Although Black students made up only $15 \%$ of the student population, they received as many as $39.3 \%$ of all out-of-school suspensions. The situation was particularly extreme for Black males; $17.6 \%$ of Black males received out-of-school suspensions compared to $9.1 \%$ of Native American/Alaskan Native males, $6.4 \%$ of Hispanic males, and 5.0\% of white males. Although rates are lower for females, the pattern was the same. Black females are much more likely to experience out-of-school suspensions (9.6\%) compared to Native American/Alaskan Native females (4.3\%), Hispanic females $(2.6 \%)$, or 
white females (1.3\%). These patterns begin as early as pre-school and continue across the students' academic careers (Ontario Ministry of Education, 2020; Owens \& McLanahan, 2020). It is interesting to note that despite the significantly higher rates of out-of-school suspension for Black students, they are less likely than their Native American/Alaskan Native, Hispanic, or white peers to carry weapons to school They are equally or less likely to have access to illegal drugs at school (U.S. Department of Education, 2019).

In addition to out-of-school suspensions, Black students are more likely to be expelled or referred to law enforcement (Civil Rights Data Collection, 2017). Black males comprised 23\% of expelled students in the 20152016 academic year, and Black females comprised 10\%, despite each group making up just $8 \%$ of enrolled students (16\% total). Similar proportions exist for referrals to law enforcement, as Black students made up $31 \%$ of students involved in law enforcement referrals or school-related arrests. While the specific reasons for suspensions, expulsions, and law referrals/arrests may vary, many directly tie to zero-tolerance policies that affect BIPOC students disproportionally to white students (The American Psychological Association Zero-tolerance Task Force, 2008).

Zero-tolerance in Schools. Zero-tolerance policies to "mandate the application of predetermined consequences, most often severe and punitive in nature, that are intended to be applied regardless of the gravity of the behavior, mitigating circumstances, or situational context" (APA Zero-tolerance Task Force, 2008, p. 852). However, there is not a singular definition. Though some situations may warrant serious consequences due to the level of risk to the student and the community, zero-tolerance policies prevent case-by-case analysis of risk, contextual variables, or consequences that may be in the best interest of students. Such policies fail to help students improve behavior, be successful, and stay in school. According to a report by the American Civil Liberties Union (ACLU, 2008), zero-tolerance policies have resulted in significant increases in suspensions, expulsions, and law enforcement referrals - often for minor offenses. In interviews, law officials raised concerns that schools often use zero-tolerance policies to 'push out' students they deem as challenging. Such an approach is particularly concerning for Black students, as research indicates that the application of zero-tolerance policies leads to stricter punishments for all students. Yet, those punishments are applied differently across ethnicity (ACLU, 2020). Specifically, school staff more often punish the objective behaviors of white students (e.g., smoking, vandalism, using obscene language). In contrast, they more often punish behavior of Black students such as 'being disrespectful,' making 
'excessive noise,' or 'acting threatening.' School professionals' subjective interpretation of these behaviors (Losen, et al., 2015) contributes to biased and exclusionary discipline.

Just as definitions of zero-tolerance policies vary, so do the behaviors targeted and consequences applied by school systems. These discrepancies can lead to systemic racism in the education system, as biases and prejudice impact interpretation of behavior and selection of consequences. Zero-tolerance policies are often subjectively interpreted and implemented. Research suggests such variations in use specifically contribute to anti-Black racism, defined as "policies and practices rooted in institutions such as, education, health care, and justice that mirror and reinforce beliefs, attitudes, prejudice, stereotyping and/or discrimination towards people of Black-African descent" (Benjamin, 2005, as cited by Black Health Alliance, 2018). As a result, zero-tolerance has led to disproportionate rates of injustice for Black students, causing a school-to-prison pipeline in which students, predominantly Black males, are pushed into the criminal justice system through suspensions and expulsions (Bailey, 2017, p.155; OME, 2020). The APA Zero-Tolerance Task Force (2008) indicated that bias impacted the implementation of zerotolerance policies, as handling of disciplinary issues was contradictory across student groups. School professionals can help end the school-to-prison pipeline, however. Understanding the intersectionality of zero-tolerance and antiBlack racism is a key step toward ending systemic racism in education.

\section{Systemic Racism in Schools}

Systemic racism may be one of the primary causes of disparity in education. Systemic racism (also referred to as institutionalized racism) is a system of assigning value and allocating opportunity based on skin color with an unfair allocation of privileges assigned to different individuals and groups, such as in education (APA, 2020; Matsuda et al., 2020). It is important to note that racism need not be 'purposeful' by individual school personnel, but biased responding by many, even when done inadvertently or 'unconsciously,' leads to systemic effects that are catastrophic for many students and communities. One push to eradicate systemic racism comes from the Black Lives Matter (BLM) movement. The BLM movement originated in 2013, aiming to eradicate systemic racism and white supremacy, and to "build local power to intervene in violence inflicted on Black communities by the state and vigilantes" (Black Lives Matter, 2020). Through this work, they draw attention to how systemic racism deprives BIPOC of fundamental human rights and dignity, in areas such as education (Howard, 2016).

BLM at School is a national coalition organizing for racial justice in education. The group cites several demands as critical to the movement, including "hire more black teachers," "mandate black history and ethnic 
studies in the K-12 curriculum," and "fund counselors, not cops" (Black Lives Matter at School, 2020). Their first demand, however, is to end zero-tolerance discipline. The Canadian chapter of the movement also presents 11 developing movements in education, including public apologies, creating community healing spaces for BIPOC students that have experienced anti-racism in schools, and creating Black advisory and student council committees (Black Lives Matter - Canada, 2020). These efforts are all important but ending zero-tolerance is an urgent educational crisis.

Ontario, Canada Case Example of Systemic Racism. Looking to dismantle systemic barriers to education, the Ontario Ministry of Education (OME; 2020) conducted a review on anti-Black racism, discord in senior leadership, and governance issues within a mid-sized school district. The study confirmed that "there has been a historical, collective absence of a call to action to stop the harmful effects of anti-Black racism and to take responsibility for the poor outcomes" of BIPOC students (OME, 2020, p.7). This review found that 2016 employee census data indicated only $25 \%$ racialized staff, countering the student body's demographics (OME, 2020). Also, they found existing policies and procedures designed to guide police interaction in schools were not working. There was a need for greater accountability by school administrators to inform and consult with parents when implementing progressive discipline that may trigger police intervention (OME, 2020). Further findings suggested school administrators needed more training with de-escalation and restorative techniques to reduce the need for police involvement in schools (OME, 2020).

The review found little evidence that parents of BIPOC students received notifications of exclusionary classroom measures or suspensions - even for students as young as pre-school age (four years old). More significantly, however, school personnel did not consistently record suspension data, despite Ministry standards. Similarly, the school did not consistently report data on race; in several reports, individuals recoding the reasons for suspensions simply recorded other, without further description. In short, between 2013 and 2019, the OME (2020, p. 9) found that $78 \%$ of the secondary school suspensions and approximately $40 \%$ of elementary school suspensions ( $n$ = 20) did not meet the definition communicated by the MOE for the use of other incident codes. Notably, BIPOC youth reported they were held to higher standards and different codes of conduct in comparison to white or other racialized students (OME, 2020, p. 10). Sadly, this example is not unique. A similar report produced within the state of Missouri also found that data on student discipline is not easily accessible (ACLU, 2017), but based on available 
data, it was clear that Black students were disciplined differently than white students, with a higher proportion of Black students experiencing exclusionary discipline or referral to law enforcement.

\section{Potential Behavior Analytic Solutions}

The evidence shows that BIPOC students are impacted at a disproportionate rate when it comes to school discipline and zero-tolerance policies (Bailey, 2017; Child Trends, 2017; Gastic, 2017, Harvard Civil Rights Project, 2000; Howard, 2016; Ontario Human Rights Committee, 2020; OME, 2020). Therefore, alternative approaches are needed. The field of behavior analysis is not yet doing enough to address large-scale cultural variables of racism (Matsuda et al., 2020; Mattaini, \& Rehfeldt, 2020; Zarcone et al., 2019). Yet, behavior analysis is ideally suited to investigate and explain the contingencies maintaining inequities in schools. Behavior analytic professionals can help to end zero-tolerance policies through the development, implementation, and support of positive, restorative interventions.

Although the field of behavior analysis can contribute to eliminating anti-Black racism in education, we know too little about the current perceptions and experiences of professionals in school settings, as related to zerotolerance policies, racism/racial inequality, or training and experience with alternative interventions. Gathering this data may reveal if school professionals already know about, use, and are comfortable with evidence-based, behavior science alternatives to zero-tolerance policies. To date, no study has investigated the experiences of school professionals implementing behavior analytic techniques to reduce racism, in alignment with the demand of BLM at School. To gather this information, a survey study was conducted.

\section{Methods}

\section{Sampling Strategy}

Purposive sampling, a non-probability sampling procedure, was utilized to set inclusion criteria for study participation. The study invited school staff members and behavior analytic professionals, working in school settings, to participate. School staff included professionals such as teachers, registered early childhood educators, psychologists, school administrators, licensed professional counselors, health care assistants. Behavior analytic professionals included Registered Behavior Technicians ${ }^{\oplus}-$ RBT $^{\circledast}$, Board Certified Assistant Behavior Analysts ${ }^{\circledR}$ $\mathrm{BCaBA}^{\circledast}$, Board Certified Behavior Analysts ${ }^{\oplus}-\mathrm{BCBA}^{\circledast}$, and Board Certified Behavior Analysts- Doctoral ${ }^{\mathrm{TM}}$ BCBA-D ${ }^{\mathrm{TM}}$. Snowball sampling increased the number of potential participants, as the recruitment information encouraged individuals to share the invitation with others (Rea \& Parker, 2014). Although this distribution method 
does not allow for a calculation of a response rate, it is consistent with other survey research conducted and disseminated within the behavior analytic literature (e.g., Taylor et al., 2019).

\section{Data Collection}

A survey, developed by the authors and set up in Qualtrics was used to collect data. It included questions both explicitly developed for this study and revised from the Anti-Racism Behavior Inventory (Pieterse et al., 2016). The survey consisted of 27 questions about: 1) participant demographics, 2) willingness to build accompliceship with BLM at School, 3) experiences with zero-tolerance policies personally and professionally, and 4) experiences discussing and intervening against racism and racial inequities in schools. Authors distributed recruitment information containing the survey link to potential participants via emails to professional contacts and through social media platforms (e.g., Facebook, Instagram, Twitter, Pinterest, LinkedIn). The recruitment information encouraged individuals receiving the emails and/or viewing the social media posts to share the study information with anyone who might be interested. Participants completing the survey could choose to enter a lottery for a $\$ 50 \mathrm{Gift}$ Card.

\section{Data Analysis}

Following the completion of the survey, data were exported from Qualtrics and imported into SPSS ${ }^{\circledR}$, a statistical software used for data analysis. Authors reviewed the data to ensure that the transfer was complete and accurate (e.g., no data were missing or transferred incorrectly). Analyses included descriptive statistics, for the data set as a whole and for select cases as appropriate (e.g., only for participants who reported to be behavior analysts).

\section{Results}

\section{Participants Demographics}

A total of 111 participants completed the survey. The majority of participants were over the age of $35(n=$ $78,70.3 \%)$ and preferred use of she/her pronouns $(n=94,84.7 \%)$. In demographics, almost two-thirds of participants reported White/Caucasian $(n=72,64.9 \%)$, and the remaining one third reported BIPOC $(n=33$, 29.7\%). BIPOC individuals reported a variety of ethnicities, i.e., Asian ( $n=9,8.1 \%)$, Hispanic or Latino $(n=2$, $1.8 \%)$, Native Hawaiian or Other Pacific Islander $(n=1,0.9 \%)$, or other $(n=9,8.1 \%)$, with $18(16.2 \%)$ reporting to be Black or African American (see Figure 1). Almost all of the participants ( $n=107,96.4 \%$ ) indicated that English was their first language. A majority reported to be from the United States $(n=79 ; 71.2 \%)$ or Canada $(n=24$;

21.6\%). However, other regions were also represented, including Europe (2\%), the Caribbean (2\%), Asia/Pacific countries (1\%), and Central and South America (1\%). It is important to note that $2 \%(n=2)$ of the participants who 
reported that they were not aware of zero-tolerance policies also indicated that they were from Europe, indicating the possibility of non-representation.

Professionally, participants included behavior analysts (i.e., BCaBAs $(n=1,0.9 \%)$, BCBAs $(n=53$, $47.7 \%)$, and BCBA-Ds $(n=11,9.9 \%))$, teachers $(n=27,9.9 \%)$, Occupational Therapists $(n=1 ; 0.9 \%)$, and other professionals $(n=18,16.2 \%)$ including RBTs, school psychologists, and school administrators. Note that these numbers do not add up to $100 \%$, as some participants indicated more than one professional association. Consistent with the inclusion criteria, all participants reported having at least some experience working or consulting in schools, with a large number of participants $(n=80,72.1 \%)$ reporting more than five years of experience within the school setting.

\section{Willingness to Build Accompliceship}

To assess the willingness of participants to build accompliceship the survey included several questions about the Black Lives in Schools movement. Of the 111 participants that completed the survey, 77 participants $(69.4 \%)$ had heard of the call to action by Black Lives Matter at School. In regard to level of support for Black Lives Matter at School, almost three-quarters of participants either agreed $(n=16,14.4 \%)$ or strongly agreed $(n=64$, $57.7 \%$ ) that they would be supportive of the movement in schools (see Figure 2). Conversely, some disagreed ( $n=$ $4,3.6 \%)$, strongly disagreed $(n=9,8.1 \%)$, or were uncertain of their level of support $(n=13,11.7 \%)$.

\section{Experience and Perception of Zero-Tolerance Overall}

The next set of questions explored participants' experience with zero-tolerance policies in their school workplaces and opinions about the effectiveness and appropriateness of such policies. The beginning of the survey included a definition of zero-tolerance to ensure respondents understood the term in relation to the questions. Eighty-six participants (77.5\%) reported that they were familiar with zero-tolerance discipline policies in schools before they participated in this survey. This result closely aligns with the number of participants who reported working in schools that had adopted zero-tolerance policies $(n=83,74.8 \%)$. Regarding participant experience with zero-tolerance discipline, 42 participants (37.8\%) indicated that they had worked in at least four schools that had a zero-tolerance disciplinary policy. Of the 111 participants, over half $(n=62,55.8 \%)$ indicated that zero-tolerance policies did not work well in schools. The majority either disagreed $(n=30,27 \%)$ or strongly disagreed $(n=42$, $37.8 \%$ ) with the idea that zero-tolerance policies make schools safer or more effective in handling disciplinary 
issues. In comparison, only a minority of participants agreed $(n=9,8.1 \%)$ or strongly agreed $(n=4,3.6 \%)$ that this would be the case. Three participants $(2.7 \%)$ indicated they preferred not to answer that question.

Almost half of participants either disagreed $(n=22,19.8 \%)$ or strongly disagreed $(n=25,22.5 \%)$ with the idea that schools and organizations should have zero-tolerance policies for some misbehavior, while one-third of participants agreed $(n=27,24.3 \%)$ or strongly agreed with this idea $(n=7,6.3 \%)$; and over one quarter were uncertain $(n=30,27.0 \%)$. Many participants reported that schools should not implement zero-tolerance policies for any problem behavior. In contrast, others supported or felt uncertain about the use of zero-tolerance in some situations.

\section{Perception of the Impact of Zero-Tolerance for BIPOC Students}

The following section asked about participants' professional experiences of zero-tolerance policies for BIPOC students, and their perceptions of the effects of these policies on their own children, if applicable. Just over one-quarter of participants $(n=29,26.1 \%)$ had children who attended schools with zero-tolerance policies. Of these participants, almost one-quarter indicated that zero-tolerance policies had been positive $(n=4,13.8 \%)$ or very positive $(n=3,10.3 \%)$ for their children, while an equal number had indicated that the policies had been negative ( $n$ $=4,13.8 \%)$ or very negative $(n=3,10.3 \%)$. Over half $(n=15,51.7 \%)$ stated that they were uncertain what the effects may have been. Interestingly, all participants reporting zero-tolerance policies as positive or very positive for their children identified as white. Regarding professional experience and perception of zero-tolerance policies for BIPOC students, over half of participants indicated zero-tolerance policies had a somewhat negative $(n=15,13.5 \%)$ or negative ( $n=52,46.8 \%$ ) impact. While these findings suggest that participants' personal experience with zerotolerance policies may not have been negative for the majority, a large proportion indicated that they have at least a somewhat negative effect on BIPOC students.

\section{Skills and Experiences in the Workplace}

The final section of the survey investigated participants' training and experiences with potential interventions to reduce racism and racial inequality. Participants indicated whether they had received training in 19 different intervention technologies that have been shown in the literature to be effective alternatives to zerotolerance (see Table 3). They also indicated whether they had training or experience training other staff to implement any of the programs listed (APA Zero-tolerance Taskforce, 2008; Boccanfuso, Kuhfeld, \& Child Trends, 2011; Pitlick, 2015). All but one participant indicated they had received training in at least one of the techniques, 
with participants reporting to have been trained in an average of 7 techniques (range 0 to 10 ). When behavior analysts were considered as a sub-group, this result was similar; behavior analysts reported training in 8 techniques (range 0 to 10$)$.

Concerning issues of racism and racial inequality, 66 participants $(59.5 \%)$ indicated that they had discussed problems related to these issues within their school workplace, with a large number $(n=43,38.7 \%)$ indicating that they often speak with colleagues about issues of racism, racial inequality, and possible solutions. However, 45 participants (40.5\%) chose not to answer both this question and another about their level of comfort discussing racism with colleagues. Of those that reported their comfort level, almost half of participants agreed $(n=26,23.4 \%)$ or strongly agreed $(n=20,18.0 \%)$ that they were comfortable discussing racism with colleagues. It is also interesting to note that 85 participants $(76.6 \%)$ indicated that their organization should have a zero-tolerance policy for racism.

While over half of participants indicated that they discussed these issues in their schools, only 11 participants $(9.9 \%)$ reported that they had collected behavioral or educational data within the past few months to identify possible racial inequities. Only 10 participants $(9.0 \%)$ conducted ABA-based interventions specifically to address racial inequalities. Results indicate that school professionals, including behavior analysts, have many evidence-based skills that may be effective alternatives to zero-tolerance policies. However, while many participants are comfortable talking about race and racial inequity solutions, they most are not collecting data or using ABAbased interventions to intervene.

\section{Discussion}

This survey examined school professionals' and behavior analysts' knowledge, experience, and perceptions of zero-tolerance policies, racism, and racial inequality. Although most participants indicated that they support Black Lives Matter at School's demand to end zero-tolerance policies and want to build accompliceship with the BLM in Schools movement, they are not always comfortable talking about race and inequities. Fewer still reported developing and/or implementing evidence-based interventions to address racism or racial inequality. Despite the efforts put forth through the current social justice movement, dismantling anti-Black racism in education is still a pressing crisis in North America. Many participants reported that these policies do not make schools safer and have a negative impact on BIPOC students. Furthermore, existing literature has indicated that zero-tolerance's effectiveness is inconsistent and highlights the need for alternative strategies to progress towards effective change 
(González et al., 2018; Harvard Civil Rights Project, 2000; Pitlick, 2015; The APA Zero-tolerance Task Force, 2008).

School professionals likely have the skills, such as using positive behavior supports, reinforcement, individualized behavior support plans, or social skills instruction, as alternatives to zero-tolerance practices, yet few are implementing those approaches to impact racial inequities. Practice guidelines, adapted from the APA ZeroTolerance Task Force (2008, pp. 857-858), can help us take action (see Table 5). From a behavior-analytic perspective, zero-tolerance policies are punishment procedures that do not produce a long-lasting effect on socially appropriate behaviors (Skiba, 1999). Exclusionary discipline of this sort does not teach new skills or build relationships as a proactive, culturally appropriate approach to school behavior issues. Most importantly, zerotolerance reinforces systemic racism for BIPOC. Widespread discipline practices of suspension, expulsion, and arrest for school behavior problems may turn students in crisis into criminal offenders (Skiba \& Rausch, 2006). Instead of using punishment-based procedures, the current literature supports implementing preventive measures or restorative justice approaches. For example, we should focus on improving classroom management, teaching socialemotional skills, involving parents and the community in the development of behavior programs, adopting early screening procedures for mental health issues, improving data collection on discipline, and ensuring effective and ongoing collaboration between educators, juvenile justice professionals, and law enforcement (Skiba \& Rausch, 2006).

Professionals wishing to reduce racism must engage in both self-reflection and uncomfortable dialogue about racism in education. Behavior science has powerful tools that can help end the school-to-prison pipeline. Reducing anti-Black racism in schools requires action, even when it feels uncomfortable. It seems there are still skill gaps or blind spots around collecting, utilizing, discussing, and intervening against racial biases, racism, and inequity in school settings. As a group, behavior analysts are not yet skillfully culturally sensitive, and need more training in inter-cultural competence (Beaulieu, Addington, \& Almeida, 2019). Purposeful collaboration and consultation with professionals experienced in this area could help (e.g., with advocates and allies of the BIPOC community or with racism researchers in other fields). Future efforts should also help pre-service professionals demonstrate the skills necessary for effective dialogue and intervention around racism, such as cultural humility (see Wright, 2019). Other efforts may focus on training behavior analysts as change agents (Conner et al., 2019), 
understanding how one's culture impacts decision-making and bias (Fong et al., 2016), and researching, experimentally, ways to reduce racism in service delivery.

\section{Limitations}

This survey had several limitations that can inform future research. First, a sample size of 111 participants may not represent the full range of behavior analysts and professionals working in schools. Replication with a larger sample and with professionals from diverse disciplines is recommended. Second, there was a possibility of response bias. Participants may have had a personal interest in decreasing punishment procedures in schools due to dissatisfaction with current social events involving BIPOC communities. Future research should replicate this study at different points in time when social disparities are not national news. Third, although zero-tolerance was defined at the beginning of the survey, some participants indicated less familiarity with this type of exclusionary discipline.

Thus, their direct experiences with such policies may have been limited. Future research can recruit participants with more extensive experiences and knowledge with zero-tolerance policies. Fourth, the length of the survey may have caused fatigue in responding. Although the average time for survey completion was 10 minutes, a shorter survey may result in fewer skipped questions. Lastly, the survey was administered during the first summer of the COVID19 pandemic, which may have also reduced participation and responding.

\section{Conclusion}

Results suggest that school professionals, including behavior analysts, want to build an accompliceship with the BLM in Schools movement. A desire to work toward shared goals of eradicating racism is an essential aspect of multidisciplinary teams working toward an equitable and supportive educational system. Yet, few respondents reported taking action to implement evidence-based interventions for racism. Some don't yet feel comfortable discussing racial inequity in their workplace. So, while professionals in school settings may have the skills and willingness to implement alternatives to exclusionary discipline, the path forward is not easy. Eradicating racial inequity will require school teams to talk about the issues and take action together. This study suggests many professionals have the necessary motivation and skills to improve outcomes for all students, particularly BIPOC students disproportionately affected by discriminatory disciplinary policies. 


\section{References}

American Civil Liberties Union. (2008). Dignity denied: The effects of “zero tolerance” polices on students' human rights. https:/www.aclu.org/sites/default/files/pdfs/humanrights/dignitydenied_november2008.pdf

American Civil Liberties Union. (2017). Missouri's pipeline of injustice: From school to prison. https://www.aclumo.org/sites/default/files/stpp_report_new_brand_with_update_oct_2018_as_pages_with_blanks.pdf

American Civil Liberties Union. (2020). Race and inequality in education. https://www.aclu.org/issues/racialjustice/race-and-inequality-education

American Psychological Association Zero Tolerance Task Force. (2008). Are zero-tolerance policies effective in the schools? An evidentiary review and recommendations. The American Psychologist, 63(9), 852-62. https://doi.org/10.1037/0003-066X.63.9.852

American Psychological Association. (2020). Racism, bias, and discrimination resources. https://www.apa.org/topics/racism-bias-discrimination

Bailey, J. (2017). From "zero-tolerance" to "safe and accepting": Surveillance and equality in the evolution of Ontario education law and policy. Education \& Law Journal, 26(2), 147-180.

Beaulieu, L., Addington, J., \& Almeida, D. (2019). Behavior analysts' training and practices regarding cultural diversity: The case for culturally competent care. Behavior Analysis in Practice, 12(3), 557-575. http://doi.org/10.1007/s40617-018-00313-6

Black Health Alliance. (2018). Anti-Black racism. https://blackhealthalliance.ca/home/antiblack-racism/

Black Lives Matter - Canada. (2020). Education demands. https://blacklivesmatter.ca/demands/

Black Lives Matter at Schools. (2020). About: Zero-tolerance. https://blacklivesmatteratschool.com/about/

Boccanfuso, C., Kuhfeld, M., \& Child Trends Incorporated. (2011). Multiple responses, promising results: Evidence-based, nonpunitive alternatives to zero tolerance (Ser. Child trends research brief). Child Trends. http://www.childtrends.org/wp-content/uploads/2011/03/Child_Trends 2011_03_01_RB_AltToZeroTolerance.pdf

Child Trends. (2017). 5 things to know about racial and ethnic disparities in special education. https://www.childtrends.org/child-trends-5/5-things-know-racial-ethnic-disparities-special-education Civil Rights Data Collection (2017). 2015-16 state and national estimations.

https://ocrdata.ed.gov/StateNationalEstimations/Estimations_2015_16 
Conners, B., Johnson, A., Duarte, J., Murriky, R., \& Marks, K. (2019). Future directions of training and fieldwork in diversity issues in applied behavior analysis. Behavior Analysis in Practice, 12(4), 767-776. https://doi.org/10.1007/s40617-019-00349-2

de Brey, C., Musu, L., McFarland, J., Wilkinson-Flicker, S., Diliberti, M., Zhang, A., \& Wang, X. (2019). Status and Trends in the Education of Racial and ethnic groups 2018 (NCES 2019-038). Washington, DC: National Center for Education Statistics U.S. Department of Education.

Fong, E. H., Catagnus, R. M., Brodhead, M. T., Quigley, S. \& Fields, S. (2016). Developing the cultural awareness skills of behavior analysts. Behavior Analysis in Practice, 9(1), 84-94. Denotes co-first authors. https://dx.doi.org/10.1007\%2Fs40617-016-0111-6

Gastic, B. (2017). Disproportionality in school discipline in massachusetts. Education and Urban Society, 49(2), 163-179. https://doi.org/10.1177/0013124516630594

González, T., Sattler, H., \& Buth, A. J. (2018). New directions in whole-school restorative justice implementation. Conflict Resolution Quarterly, 36(3), 207-220. https://doi.org/10.1002/crq.21236

Harvard Civil Rights Project \& Advancement Project. (2000, June). Opportunities suspended: The devastating consequences of zero-tolerance and school discipline policies. Report from a National Summit on Zerotolerance, Washington, DC.

Howard, T. C. (2016). Why black lives (and minds) matter: Race, freedom schools \& the quest for educational equity. Journal of Negro Education, 85(2), 101-113. https://doi.org/10.7709/jnegroeducation.85.2.0101

Indigenous Action. (2014, May 4). Accomplices not allies: Abolishing the ally industrial complex [Blog post]. https://www.indigenousaction.org/accomplices-not-allies-abolishing-the-ally-industrial-complex/

Losen, D., Hodson, C., Keith II, M. A., Morrison, K., Belway, S. (2015). Are we closing the school discipline gap? (The Center for Civil Rights Remedies). Los Angeles, CA: The University of California.

Matsuda, K., Garcia, Y., Catagnus, R., \& Brandt, J. A. (2020). Can behavior analysis help us understand and reduce racism? A review of the current literature. Behavior Analysis in Practice, 13, 336-347. https://doi.org/10.1007/s40617-020-00411-4

Mattaini, M. A., \& Rehfeldt, R. A. (2020). Rendezvous with truth and discovery. Behavior and Social Issues, 29, 1 14. https://doi.org/10.1007/s42822-020-00034-y 
National Association of Education. (2020). Building relationship and community to prevent and address conflict: Ending the school to prison pipeline. https://neaedjustice.org/ending-the-school-to-prison-pipeline/

Ontario Human Rights Commission. (2020). The Ontario safe schools act: School discipline and discrimination. http://www.ohrc.on.ca/en/ontario-safe-schools-act-school-discipline-and-discrimination

Ontario Ministry of Education. (2020). Peel district school board review - Ministry of Education. http://www.edu.gov.on.ca/eng/new/review-peel-district-school-board-report-en.pdf

Owens, J., \& McLanahan, S. S. (2020). Unpacking the drivers of racial disparities in school suspension and expulsion. Social Forces, 98(4), 1548-1577. https://doi.org/10.1093/sf/soz095

Pieterse, A. L., Utsey, S. O., Miller, M. J., (2016). Development and initial validation of the anti-racism behavioral inventory (ARBI). Counselling Psychology. Quarterly, 29 (4), 356-381. https://doi.org/10.1080/09515070.2015.1101534

Pitlick, N. E. (2015). Alternatives to zero tolerance policies affecting students of color: A systematic review. https://sophia.stkate.edu/msw_papers/502

Rea, L. M., \& Parker, R. A. (2014). Designing and conducting survey research: A comprehensive guide (Fourth). Jossey-Bass, a Wiley brand.

Skiba, R., \& Peterson, R. (1999). The dark side of zero tolerance: Can punishment lead to safe schools? The Phi Delta Kappan, 80(5), 372-382.

Skiba, R. J., \& Rausch, M. K. (2006). Zero-tolerance, suspension, and expulsion: Questions of equity and effectiveness. In C. M. Evertson \& C. S. Weinstein (Eds.), Handbook of classroom management: Research, practice, and contemporary issues (pp. 1063-1089). Mahwah, NJ: Erlbaum.

Taylor, B. A., LeBlanc, L. A., \& Nosik, M. R. (2019). Compassionate care in behavior analytic treatment: Can outcomes be enhanced by attending to relationships with caregivers? Behavior Analysis in Practice, 12(3), 654-666. https://doi.org/10.1007/s40617-018-00289-3

Wright, P. I. (2019). Cultural humility in the practice of applied behavior analysis. Behavior Analysis in Practice, 12(4), 805-809. https://doi.org/10.1007/s40617-019-00343-8

Zarcone, J., Brodhead, M. \& Tarbox, J. (2019). Beyond a call to action: An introduction to the special issue on diversity and equity in the practice of behavior analysis. Behavior Analysis in Practice, 12, 741-742. https://doi.org/10.1007/s40617-019-00390-1 
ENDING THE SCHOOL-TO-PRISON-PIPELINE

\section{Table 1}

\section{Level of Agreement with Survey Questions}

Level of Agreement

\begin{tabular}{|c|c|c|c|c|c|c|}
\hline \multirow[b]{2}{*}{ Survey Items } & \\
\hline & $\begin{array}{l}\text { Strongly } \\
\text { Disagree }\end{array}$ & Disagree & Uncertain & Agree & $\begin{array}{l}\text { Strongly } \\
\text { Agree }\end{array}$ & $\begin{array}{l}\text { Prefer } \\
\text { Not to } \\
\text { Answer }\end{array}$ \\
\hline $\begin{array}{l}\text { How strongly would you support a } \\
\text { movement like Black Lives Matter at } \\
\text { Schools? }\end{array}$ & $\begin{array}{l}8.1 \% \\
(n=9)\end{array}$ & $\begin{array}{l}3.6 \% \\
(n=4)\end{array}$ & $\begin{array}{l}11.7 \% \\
(n=13)\end{array}$ & $\begin{array}{l}14.4 \% \\
(n=16)\end{array}$ & $\begin{array}{l}57.7 \% \\
(n=64)\end{array}$ & $\begin{array}{l}4.5 \% \\
(n=5)\end{array}$ \\
\hline $\begin{array}{l}\text { I often speak to my colleagues about } \\
\text { the problem of racism, racial inequity, } \\
\text { and what we can do about it. }\end{array}$ & $\begin{array}{c}4.5 \% \\
(n=5)\end{array}$ & $\begin{array}{c}9.9 \% \\
(n=11)\end{array}$ & $\begin{array}{c}6.3 \% \\
(n=7)\end{array}$ & $\begin{array}{l}23.4 \% \\
(n=26)\end{array}$ & $\begin{array}{l}15.3 \% \\
(n=17)\end{array}$ & $\begin{array}{c}40.5 \% \\
(n=45)\end{array}$ \\
\hline $\begin{array}{l}\text { I feel comfortable talking about racism } \\
\text { at work. }\end{array}$ & $\begin{array}{l}5.4 \% \\
(n=6)\end{array}$ & $\begin{array}{l}3.6 \% \\
(n=4)\end{array}$ & $\begin{array}{l}8.1 \% \\
(n=9)\end{array}$ & $\begin{array}{l}23.4 \% \\
(n=26)\end{array}$ & $\begin{array}{c}18 \% \\
(n=20)\end{array}$ & $\begin{array}{c}40.5 \% \\
(n=45)\end{array}$ \\
\hline $\begin{array}{l}\text { Schools and organizations should have } \\
\text { zero-tolerance policies for some } \\
\text { misbehavior. }\end{array}$ & $\begin{array}{l}22.5 \% \\
(n=25)\end{array}$ & $\begin{array}{l}19.8 \% \\
(n=22)\end{array}$ & $\begin{array}{c}27 \% \\
(n=30)\end{array}$ & $\begin{array}{c}24.3 \% \\
(n=27)\end{array}$ & $\begin{array}{c}6.3 \% \\
(n=7)\end{array}$ & $0 \%$ \\
\hline
\end{tabular}

Level of Agreement

\begin{tabular}{lcccccc}
\cline { 2 - 6 } \multicolumn{1}{c}{ Survey Items } & Strongly & Disagree & Agree & $\begin{array}{c}\text { Strongly } \\
\text { Agree }\end{array}$ & $\begin{array}{c}\text { Not } \\
\text { Applicable }\end{array}$ & $\begin{array}{c}\text { Prefer } \\
\text { Not to } \\
\text { Answer }\end{array}$ \\
\hline $\begin{array}{l}\text { Zero-tolerance policies generally make } \\
\text { schools safer and more effective in } \\
\text { handling disciplinary issues }\end{array}$ & $\begin{array}{c}37.8 \% \\
(n=42)\end{array}$ & $\begin{array}{c}27 \% \\
(n=30)\end{array}$ & $\begin{array}{c}8.1 \% \\
(n=9)\end{array}$ & $\begin{array}{c}3.6 \% \\
(n=4)\end{array}$ & $\begin{array}{c}4.5 \% \\
(n=5)\end{array}$ & $\begin{array}{c}2.7 \% \\
(n=3)\end{array}$
\end{tabular}

Note. This tables provides data from the participant survey indicating level of agreement. 
ENDING THE SCHOOL-TO-PRISON-PIPELINE

19

Table 2

Participant Perception of Level of Impact

\begin{tabular}{|c|c|c|c|c|c|}
\hline \multirow[b]{2}{*}{ Survey Items } & \multicolumn{5}{|c|}{ Level of Impact } \\
\hline & Negative & $\begin{array}{l}\text { Somewhat } \\
\text { Negative }\end{array}$ & $\begin{array}{l}\text { Neither Positive } \\
\text { and/or Negative }\end{array}$ & $\begin{array}{l}\text { Somewhat } \\
\text { positive }\end{array}$ & Positive \\
\hline $\begin{array}{l}\text { How well has zero-tolerance policies worked } \\
\text { in schools? }\end{array}$ & $\begin{array}{c}32.4 \% \\
(n=36)\end{array}$ & $\begin{array}{c}23.4 \% \\
(n=26)\end{array}$ & $\begin{array}{c}26.1 \% \\
(n=29)\end{array}$ & $\begin{array}{c}14.4 \% \\
(n=16)\end{array}$ & $\begin{array}{c}2.7 \% \\
(n=3)\end{array}$ \\
\hline $\begin{array}{l}\text { How have zero-tolerance policies impacted } \\
\text { Black, indigenous, or students of color? }\end{array}$ & $\begin{array}{c}46.8 \% \\
(n=52)\end{array}$ & $\begin{array}{c}13.5 \% \\
(n=15)\end{array}$ & $\begin{array}{c}25 \% \\
(n=28)\end{array}$ & $\begin{array}{c}10 \% \\
(n=11)\end{array}$ & $\begin{array}{c}7 \% \\
(n=8)\end{array}$ \\
\hline $\begin{array}{l}\text { For your child(ren), please rate how zero- } \\
\text { tolerance impacted them? }\end{array}$ & $\begin{array}{l}13.8 \% \\
(n=4)\end{array}$ & $\begin{array}{l}10.3 \% \\
(n=3)\end{array}$ & $\begin{array}{l}51.7 \% \\
(n=15)\end{array}$ & $\begin{array}{l}10.3 \% \\
(n=3)\end{array}$ & $\begin{array}{l}13.8 \% \\
(n=4)\end{array}$ \\
\hline
\end{tabular}

Note. This table provides data from the participant survey indicating participant perception of level of impact of zero-tolerance policies in schools. 
ENDING THE SCHOOL-TO-PRISON-PIPELINE

Table 3

Skill Experience Summary

\begin{tabular}{|c|c|c|}
\hline Skills & $N$ & $\%$ \\
\hline Reinforcing positive behavior ${ }^{3}$ & 95 & $85.5 \%$ \\
\hline Use of praise for positive behavior ${ }^{3}$ & 89 & $80.2 \%$ \\
\hline Individualized behavior support ${ }^{1,2}$ & 87 & $78.4 \%$ \\
\hline Training staff to implement any of the programs listed & 87 & $78.4 \%$ \\
\hline Positive behavior support interventions $s^{2,3}$ & 86 & $77.5 \%$ \\
\hline Social skill instruction ${ }^{2,3}$ & 81 & $73.0 \%$ \\
\hline Social and emotional learning programs ${ }^{1}$ & 81 & $73.0 \%$ \\
\hline Role play and practice of positive behaviors ${ }^{1}$ & 80 & $72.1 \%$ \\
\hline Modeling or video modeling of skills ${ }^{1}$ & 77 & $69.4 \%$ \\
\hline Interactive teaching of social or emotional skills ${ }^{2,3}$ & 64 & $57.7 \%$ \\
\hline Cognitive behavioral training ${ }^{2,3}$ & 40 & $36.0 \%$ \\
\hline Other & 10 & $9.0 \%$ \\
\hline
\end{tabular}

Note. This table presents data on the skills that participants report to have training in, that can serve as alternatives to zero-tolerance policies. Other skills reported included Acceptance and Commitment Therapy, Behavior Skills Training, Psychological Flexibility, Teacher Preparation, Discrete Trail Training, Functional Communication Training, Trauma Informed Care.

${ }^{1}$ APA Zero-tolerance Taskforce (2008); ${ }^{2}$ Child Trends (2011); ${ }^{3}$ Pitlick (2015). 


\section{Table 4}

\section{Yes, No Response Summary for Survey Questions}

\begin{tabular}{|c|c|c|c|}
\hline \multirow[b]{2}{*}{ Survey Items } & \multicolumn{3}{|c|}{ Yes, No Responses } \\
\hline & Yes & No & $\begin{array}{l}\text { Prefer } \\
\text { Not to } \\
\text { Answer }\end{array}$ \\
\hline $\begin{array}{l}\text { My organization should have a zero-tolerance employee } \\
\text { policy for racism? }\end{array}$ & $\begin{array}{l}76.6 \% \\
(n=85)\end{array}$ & $\begin{array}{l}23.4 \% \\
(n=26)\end{array}$ & $0 \%$ \\
\hline $\begin{array}{l}\text { Are you familiar with 'zero-tolerance' discipline policies in } \\
\text { schools? }\end{array}$ & $\begin{array}{l}77.5 \% \\
(n=86)\end{array}$ & $\begin{array}{l}22.5 \% \\
(n=25)\end{array}$ & $0 \%$ \\
\hline $\begin{array}{l}\text { Have you read or heard of the current calls to action by } \\
\text { Black Lives Matter at Schools, a national coalition } \\
\text { organizing for racial justice in education? }\end{array}$ & $\begin{array}{l}69.4 \% \\
(n=77)\end{array}$ & $\begin{array}{l}30.6 \% \\
(n=34)\end{array}$ & $0 \%$ \\
\hline $\begin{array}{l}\text { In the past three months, discussed problems of race or } \\
\text { racial inequity or racism in your school? }\end{array}$ & $\begin{array}{l}59.5 \% \\
(n=66)\end{array}$ & $\begin{array}{l}40.5 \% \\
(n=45)\end{array}$ & $0 \%$ \\
\hline $\begin{array}{l}\text { Do you have children who attend a school with zero- } \\
\text { tolerance policies? }\end{array}$ & $\begin{array}{l}26.1 \% \\
(n=29)\end{array}$ & $\begin{array}{l}72.1 \% \\
(n=80)\end{array}$ & $\begin{array}{l}1.8 \% \\
(n=2)\end{array}$ \\
\hline $\begin{array}{l}\text { In the past three months, collected behavioral or educational } \\
\text { data to identify possible racial inequity? }\end{array}$ & $\begin{array}{c}9.9 \% \\
(n=11)\end{array}$ & $\begin{array}{c}90.1 \% \\
(n=100)\end{array}$ & $0 \%$ \\
\hline $\begin{array}{l}\text { Conducted an ABA intervention that may help reduce racial } \\
\text { inequity in the school? }\end{array}$ & $\begin{array}{c}9 \% \\
(n=10)\end{array}$ & $\begin{array}{c}91 \% \\
(n=101)\end{array}$ & $0 \%$ \\
\hline
\end{tabular}

Note. This table provides data from the participant survey indicating percentages of participants who indicated agreement or disagreement with statements made in survey questions. 
ENDING THE SCHOOL-TO-PRISON-PIPELINE

Table 5

Practice Guideline Summary

Guidelines

Foster a collaborative school team approach incorporating increased flexibility for implementing preventative measures to eliminate "one size fits all" discipline.

Ensure consistent transparency in communicating discipline incidents with parents and caregivers.

Consistently define violations and appropriately train all staff on proactive or reactive steps.

Continuously evaluate current school discipline or violence prevention strategies and modify as necessary.

Identify high-risk youth and use threat assessments procedures to develop a continuum of alternatives for meaningful interventions.

Hire trained professionals (e.g., mental health counselors who are adequately equipped to address the root of the problem behavior, to better account for minor violations caused by developmental contributions.

Note. Adapted from APA Zero-tolerance Task Force (2008, pp. 857-858) 
ENDING THE SCHOOL-TO-PRISON-PIPELINE

\section{Figure 1}

Participant's Race/Ethnicity Summary

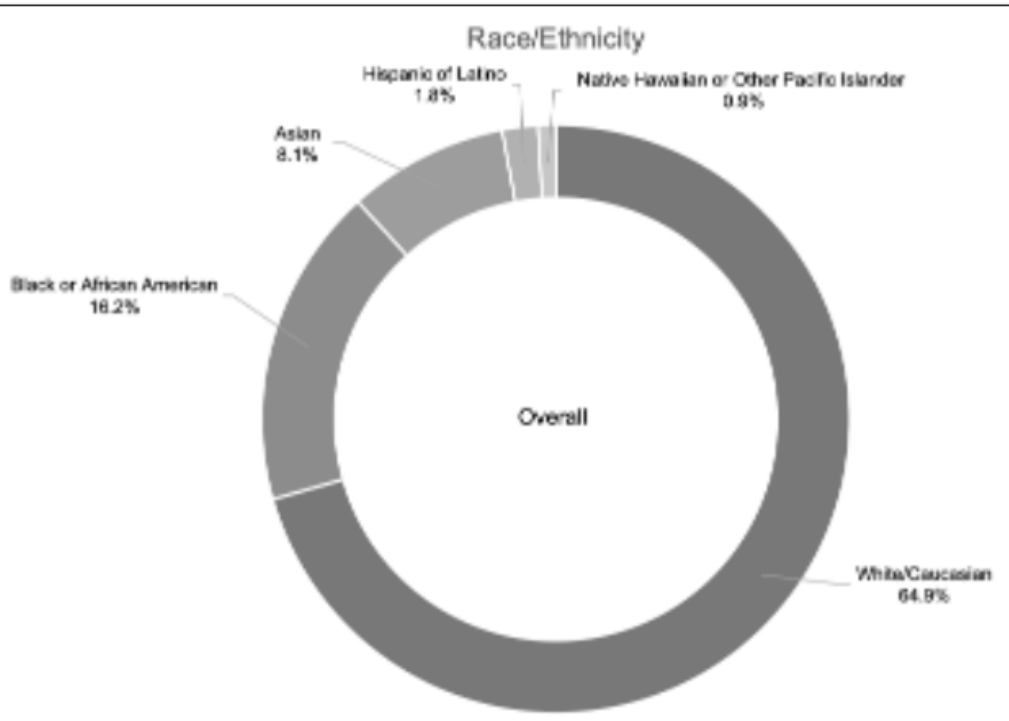

Nore. Total number of particiberts who responded inchued 111: BCBAs in $=53$; $B$ CaBAs $(n-1) ; 8 C B A-D$ in -11$)$ :

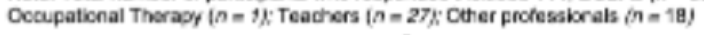

\section{Figure 2}

\section{Summary of Key Results}

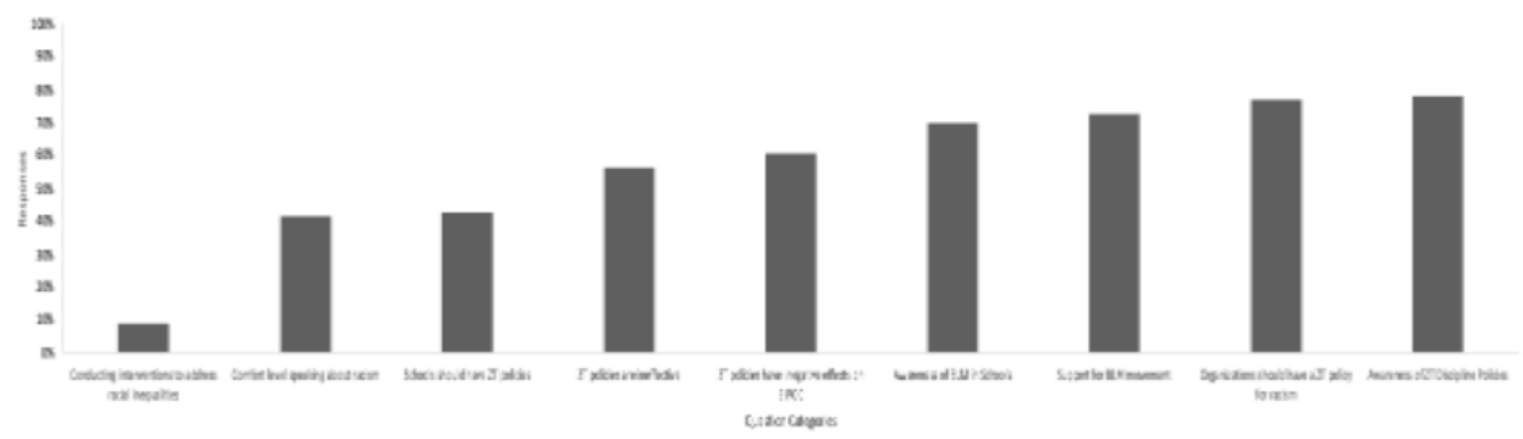

Note. The information shown displays participant's responses to each question category. 
